IZA DP No. 4880

Gender and the Influence of Peer Alcohol Consumption on Adolescent Sexual Activity

Glen R. Waddell

April 2010 


\title{
Gender and the Influence of Peer Alcohol Consumption on Adolescent Sexual Activity
}

\author{
Glen R. Waddell \\ University of Oregon \\ and IZA
}

\section{Discussion Paper No. 4880}

April 2010

IZA

P.O. Box 7240

53072 Bonn

Germany

Phone: +49-228-3894-0

Fax: +49-228-3894-180

E-mail: iza@iza.org

Any opinions expressed here are those of the author(s) and not those of IZA. Research published in this series may include views on policy, but the institute itself takes no institutional policy positions.

The Institute for the Study of Labor (IZA) in Bonn is a local and virtual international research center and a place of communication between science, politics and business. IZA is an independent nonprofit organization supported by Deutsche Post Foundation. The center is associated with the University of Bonn and offers a stimulating research environment through its international network, workshops and conferences, data service, project support, research visits and doctoral program. IZA engages in (i) original and internationally competitive research in all fields of labor economics, (ii) development of policy concepts, and (iii) dissemination of research results and concepts to the interested public.

IZA Discussion Papers often represent preliminary work and are circulated to encourage discussion. Citation of such a paper should account for its provisional character. A revised version may be available directly from the author. 
IZA Discussion Paper No. 4880

April 2010

\section{ABSTRACT \\ Gender and the Influence of Peer Alcohol Consumption on Adolescent Sexual Activity*}

I consider the alcohol consumption of opposite-gender peers as explanatory to adolescent sexual intercourse and demonstrate that female sexual activity is higher where there is higher alcohol consumption among male peers. This relationship is robust to school fixed effects, cannot be explained by broader cohort effects or general anti-social behaviors in male peer groups, and is distinctly different from any influence of the alcohol consumption of female peers which is shown to have no influence on female sexual activity. There is no evidence that male sexual activity responds to female-peer alcohol consumption.

JEL Classification: J13, I12

Keywords: sex, alcohol, adolescent, peer, risky behavior

Corresponding author:

Glen R. Waddell

Department of Economics

University of Oregon

Eugene, OR 97403-1285

USA

E-mail: waddell@uoregon.edu

\footnotetext{
* I thank Scott Carrell, Angela Dills, Jason Fletcher, Hilary Hoynes, Jason Lindo, Doug Miller, Inas Rashad-Kelly, Daniel Rees, Larry Singell, Joe Stone, and seminar participants at UC-Davis and the Annual Meeting on the Economics of Risky Behaviors for beneficial comments. Any errors remain my responsibility.
} 
Aside from the direct risks associated with adolescent sexual activity (not to mention those of alcohol), long-lasting detrimental outcomes have been associated with promiscuity (e.g., Sabia and Rees (2009)) and point to the need to better understand the underlying determinants of such risky behavior in adolescent populations. With this paper I move the literature toward understanding the role of peers in determining the propensity for adolescent youth to engage in heterosexual intercourse, specifically focusing on the alcohol consumption of opposite-gender peers. Compared to the existing literature, this is a broader perspective on what might constitute the relevant alcohol-related influences on adolescent sexual activity. Given the potential complexity of peer-to-peer relationships, however, and the particularly complicated sexual relationships they experience, the role that peers play within this exchange is of considerable interest and importance.

While there are examples in the related literature that establish that alcohol consumption and sexual intercourse tend to correlate positively in adolescents, establishing any mechanism by which alcohol might be encouraging sexual behavior has been somewhat challenging. The difficulty in establishing a causal role for alcohol, for example, arises from the potential that one's consumption of alcohol and one's sexual activity vary with some common attribute that is unobserved by the econometrician (e.g., low risk aversion, high discount rates). Yet, without establishing the existence and nature of any causal relationships, the analysis of public policy on such important outcomes as teenage pregnancy, sexually transmitted disease, or other associated outcomes, might be considered incomplete and the policy prescriptions imprecise.

The focus of this analysis considers the relationship between alcohol and sexual activity from a different perspective than has been the standard in the literature and, thus, the resulting empirical considerations are somewhat different. In particular, I exploit the bilateral nature of sexual intercourse - that sexual intercourse involves both a male and female participant - not asking whether one's own alcohol consumption increases one's own propensity to engage in sexual intercourse but, rather, whether this propensity increases with the drinking behavior of one's opposite-gender peers. Given the difficulty posed in finding credible identification strategies to bring to bear on the question of whether one's own alcohol consumption increases one's own propensity to engage in sexual intercourse, that the arguable exogeneity of the key variable of interest here partially mitigates the challenges that have plagued previous studies and may speak back into the broader question of causality running from alcohol use to sexual activity, albeit indirectly and from a slightly different perspective.

Given the nature of coital relations, there is little reason to doubt that opposite-gender peers matter in some broad sense. Whether and how the alcohol consumption of these peers matters, however, is an important empirical question on which the literature has heretofore been silent. On approach, I recognize that any underlying peer effect governing the complexity of this relationship may itself be nontrivial, as male and female youth can and do differ in their motivations toward sexual activity. For example, among respondents in the National Longitudinal Study of Adolescent Health (i.e., Add Health) there are significant gender differences in views regarding sexual activity. ${ }^{1}$ In particular, Add Health respondents

\footnotetext{
${ }^{1}$ The Add Health project is a program project designed by J. Richard Udry (PI) and Peter Bearman, and funded by grant P01-HD31921 from the National Institute of Child Health and Human Development to the Carolina Population Center, University of North Carolina at Chapel Hill, with cooperative funding participation by the National Cancer Institute; the National Institute of Alcohol Abuse and Alcoholism; the National
} 
who are fifteen or older at the time of the survey are asked a series of questions regarding how they would expect to feel if they were to have sexual intercourse. Through these questions, boys reveal that they are relatively more agreeable to statements such as "If you had sexual intercourse, your friends would respect you more," "..., it would make you more attractive to the opposite sex," and "..., you would feel less lonely." Girls, on the other hand, appear more motivated - and negatively so - by the considerations of others, being more agreeable to "If you had sexual intercourse, your partner would lose respect for you," "..., afterward, you would feel guilty," and "..., it would upset your mother/father." Clearly, if such reflections of preference and belief actually motivate sexual behavior, gender difference in any interactions of sexual behavior and the influence of peers would not be surprising. ${ }^{2}$

In the end, I document that the alcohol consumption of opposite-gender peers can matter to one's sexual activity but that this relationship is strongly gender dependent. In particular, in both pooled and within-school identification strategies I find that the sexual activity of adolescent females systematically varies with the alcohol consumption of their male peers, and that no such pattern exists for adolescent males. In sensitivity analyses, I report that this relationship is distinctly different from any influence of same-gender-peer alcohol consumption. In fact, comparable measures of female-peer drinking contribute very little to explaining female sexual activity. More general anti-social male behaviors also fail to explain sexual behavior in female adolescents, suggesting all the more that the alcohol consumption may be causing increases in female sexual activity. Further, the influence of alcohol-consuming male peers is found to attenuate in homosexuals.

While I will keep from making claims of having identified an estimate of the causal relationship, the evidence I present is compelling and the causal story remains a viable candidate for explaining the empirical regularities revealed. In the following section I briefly consult the most-relevant literature in order to provide some context for interpreting the analysis and, in Section 2, I describe the data to be used - the "In-Home" component of the Add Health survey. In Section 3 I present the empirical strategy more formally, followed by a discussion of the empirical results in Section 4. In Section 4 I also report the results of several sensitivity analyses which collectively speak to the robustness of the baseline specifications. A concluding discussion appears in Section 6.

Institute on Deafness and Other Communication Disorders; the National Institute on Drug Abuse; the National Institute of General Medical Sciences; the National Institute of Mental Health; the National Institute of Nursing Research; the Office of AIDS Research, NIH; the Office of Behavior and Social Science Research, NIH; the Office of the Director, NIH; the Office of Research on Women's Health, NIH; the Office of Population Affairs, DHHS; the National Center for Health Statistics, Centers for Disease Control and Prevention, DHHS; the Office of Minority Health, Centers for Disease Control and Prevention, DHHS; the Office of Minority Health, Office of Public Health and Science, DHHS; the Office of the Assistant Secretary for Planning and Evaluation, DHHS; and the National Science Foundation. Persons interested in obtaining data files from The National Longitudinal Study of Adolescent Health should contact Add Health Project, Carolina Population Center, 123 West Franklin Street, Chapel Hill, NC 27516-2524 (email: addhealth@unc.edu). More information on the design of Add Health can be found at http://www.cpc.unc.edu/projects/addhealth/design.

${ }^{2}$ These responses are summarized in Table 1, with log-odds regression coefficients from ordered logit models that compare male and female adolescents on their responses to these survey questions. In each case, these gender-differences in held views regarding sexual activity are statistically significant. 


\section{Literature}

While a large literature exists outside of attempts to determine the role for alcohol in sexual activity, the recent literature has focused more on the unpacking of this relationship, and with somewhat mixed results. For example, adopting an instrumental-variables approach (i.e., instrument for drinking with state-level variation in alcohol-related policy and expenditures), Rees, Argys and Averett (2001) offer some evidence of causation running from alcohol use to sexual intercourse in the male Add Health sample, but include that "the positive correlation between substance use and risky sexual behavior can, more often than not, be attributed to the influence of unobservables." Likewise, controlling for the potential endogeneity, Sen (2002) offers evidence that own alcohol use is causally predictive of an increased likelihood of sexual intercourse in adolescents in the 1997 National Longitudinal Study of Youth (NLSY97). While these arguments for a causal role are suggestive, certainly, Rashad and Kaestner (2004) calls each into question on methodological grounds, and argues against the identification strategies in both Rees, Argys and Averett (2001) and Sen (2002), ultimately concluding that "in spite of recent attempts to estimate the causal relationship between substance use and sexual behavior, the causal relationship [...] remains unknown." 3

With such a view maintained, related literatures and much public policy - where it is already quite common to operate under the assumption that a causal role does exist might be seen as somewhat ahead of our current understanding of the relationship. For example, Chesson, Harrison and Kassler (2000) exploit variation in alcohol taxes and legal drinking ages to investigate risky sexual activity, with the operating presumption being that a more restrictive alcohol policy reduces alcohol consumption, which in turn decreases risky sexual activity. More recently, Carpenter (2005) has also suggested a causal role for alcohol in adolescent sexual activity as he documents a systematic relationship between state-level "zero tolerance" drunk driving laws and reductions in gonorrhea rates in treated populations of youth. Of course, for these and other empirical strategies (e.g., Dee (2001), Sen (2003), and, Lacruz, Lacruz and Moreno (2009)), the mechanism by which drinking and sexual behavior evolves is less important than whether there is an empirical relationship at all, conditional on covariates.

We see the current investigation as informing this underlying relationship in important ways that both sheds light on a potential mechanism through which these relationships unfold and may justify new empirical strategies that exploit the information contained in opposite-gender peer behaviors. For example, it may be a somewhat myopic view to consider that variation in alcohol-related policy influences one's sexual outcomes through the policy's influence on one's own drinking behavior. In a relatively clean empirical setting, I am able to demonstrate that there is explanatory power specifically in opposite-gender alcohol use,

\footnotetext{
${ }^{3}$ Using bivariate probit and individual fixed effects within the NLSY97 sample, Markowitz, Kaestner and Grossman (2005) also find no causal role for alcohol use in determining whether or not a teenager has sex, but do find some evidence that alcohol use lowers the use of contraception among sexually active teens. Grossman and Markowitz (2005) have also suggested that while alcohol use does not increase the likelihood of having sex or of having multiple partners, it can be associated with unprotected sex among sexually active teens in a causal way. Similarly, one might consider the existing research associating alcohol with other outcomes or with risky behaviors more generally (e.g., Krauth (2005), Bray (2005), Clark and Loheac (2007), Renna (2007), and, Heckman, Pinto and Wang (2008)).
} 
and that the underlying mechanism may be operating in the interaction of gender-specific relationships between sexual relations and alcohol consumption.

\section{Data}

For our purpose, the National Longitudinal Study of Adolescent Health is a particularly fitting collection of information on adolescent behaviors as it is designed to investigate adolescent health and risk behaviors. The "Add Health" project is widely considered to be the largest and most comprehensive survey of adolescents ever undertaken, with a stratified sample of 80 high schools collectively representative of the U.S. school system with respect to region of country, urbanicity, school size, school type, and ethnicity. For each of these schools, "feeder" schools (52 in total) were selected on the basis of student contributions to the chosen high school. An in-school questionnaire was administered to almost all students in sampled schools between September 1994 and April 1995, and a random sample was selected from each of these schools for more detailed interviews, conducted in the respondents' homes between April and December 1995. It is this detailed "In-Home Survey" that I adopt. A total of 20,745 adolescents were interviewed for the Wave I In-Home Survey. Of these, however, 376 have no school identities and an additional 504 have uninterpretable grade levels. As these attributes are crucial to subsequent identification strategies, they are removed from the analysis.

Of the 19,865 respondents with school and grade-level information, several did not answer key questions, such as "Over the past 12 months, on how many days did you drink five or more drinks in a row?" or "... on how many days have you gotten drunk or 'very, very high' on alcohol?" The sample adopted constitutes roughly 94 percent of the usable data. Summary statistics by gender are shown in Table $2 .{ }^{4}$ Since I am relying on self-reported participation in potentially sensitive areas of disclosure, one should note that for sensitive topics (e.g., sexual behavior and alcohol use) survey respondents listened to pre-recorded questions through earphones and entered their answers directly on laptops in order to maintain confidentiality and to minimize the potential for interviewer or parental influence. I also note that rates of risky behaviors reported in Add Health are consistent with those measured in other sources (see Mocan and Tekin (2005), Mocan and Tekin (2006), and Tekin and Markowitz (2008)), lending a certain confidence in their use.

\footnotetext{
${ }^{4}$ This sample size also reflects that I dropped all (nine) eleven-year-old respondents, none of which had reported any alcohol consumption or having had sexual intercourse. Sample weights are available to correct for design effects and the unequal probability of an individual's selection. All results reported are robust to estimating with sample weights..
} 


\section{Empirical model}

I follow the existing literature in running specifications separately by gender. ${ }^{5}$ In particular, I will consider modeling the individual's sexual behavior in a form such as,

$$
\text { Sex } x^{\star}=\beta_{0}+\beta_{1} \text { OwnDrink }+\beta_{2} \text { PeerDrink }+\gamma X+\epsilon,
$$

where $S e x^{\star}$ is a latent variable that links to the observed binary outcome of sexual intercourse, and $\operatorname{Sex}=1$ will capture that the individual reports having had sexual intercourse within twelve months of the interview date (i.e., $S e x^{\star}>0$ ). Specifically, the available survey question specifically queries sexual relationships by following the query "Have you ever had sexual intercourse?" with the qualifier, "When I say sexual intercourse, I mean when a male inserts his penis into a female's vagina." As such, there is arguably little if any uncertainty in how $S e x$ is to be (or was) interpreted.

In Eq. (1), the individual's own drinking behavior will be captured by OwnDrink, while PeerDrink will capture the drinking behavior of the individual's opposite-gender peers. OwnDrink is included as it will remain important to hold constant one's own drinking behavior as I draw out of the data how sexual activity varies with PeerDrink. However, note that interpreting this relationship is challenging given the suspected endogeneity plaguing $\hat{\beta}_{1}$. (Given this expected endogeneity, I perform sensitivity tests on the variable of interest, $\hat{\beta}_{2}$, by the inclusion of OwnDrink, and find $\hat{\beta}_{2}$ is very stable across specifications that include or do not include OwnDrink.) In (1), $X$ will capture individual and other aggregate characteristics that have been used in previous analysis or are otherwise expected to explain variation in sexual activity and $\epsilon$ is the error term, which includes age fixed effects. (In across-school specifications, grade-level fixed effects will also be included.) Throughout the analysis, standard errors are corrected for clustering at the school level.

\subsection{OwnDrink and PeerDrink defined}

Within the Add Health dataset are several alternatives to how one might measure drinking behaviors - both OwnDrink and PeerDrink. With little defensible reason for choosing one over another, I report results across five specifications that adopt alternative measures. Roughly half of all respondents report to have never had a drink of beer, wine, or liquor. Among the participant, however, the adopted drinking measures span an intensity of alcohol attachment in an appealing way. Reporting results across such a range will also provide some information about the influence of various drinking intensities. These measures are defined in Table 3, with summary breakdowns provided by gender. ${ }^{6}$

\footnotetext{
${ }^{5}$ Separating reference groups by sex is also common when considering peer effects in single behaviors (e.g., Kooreman (2007), Kling, Ludwig and Katz (2005), Soetevent and Kooreman (2006), Clark and Loheac $(2007))$.

${ }^{6} \mathrm{On}$ one end of the spectrum of intensity are those who responded with "1 or 2 days" or more when asked, "During the past 12 months, on how many days did you drink alcohol?" This may be closest to what most would consider admitting to "dabbling" with alcohol consumption. From there, the progression is not prescribed. That said, a reasonable range of categorizations might be, 2) the respondent replied with at least "1 or 2 days" when asked, "Over the past 12 months, on how many days have you gotten drunk or "very, very high' on alcohol?" 3) the respondent replied with either "once a month or less" or "2 to 3 days a month"
} 
While the Add Health dataset provides a measure of each individual's friendships (i.e., the reporting of up to five same-gender friends and five opposite-gender friends), adopting this set of friends as the individual's peers introduces some empirical concerns. Even ignoring the potential measurement error (e.g., one's friends may exceed five in number, one's friends need not fall within the Add Health survey), that friends are chosen is problematic. For example, were the attributes or behaviors of one's declared friends (e.g., their drinking patterns) to correlate with one's behavior (e.g., being sexually active), it would be difficult to distinguish between the attributes of these friends having some influence over outcomes as opposed to the friends having been chosen for their attributes. ${ }^{7}$ While a growing body of work adopts the existence of friends in the Add Health data as an opportunity to analyze the influence of friends on outcomes, these relationships should be analyzed with these concerns in mind. ${ }^{8}$

I avoid this particular bias by defining individual $i$ 's opposite-gender peer group as all opposite-gender students in the sample who are in the same grade and school as $i$. Thus, in female (male) samples, I allow the sexual activity of individual $i$ to vary with the drinking behavior of the average male (female) student in the same grade at the same school. ${ }^{9}$ Given these definitions, (1) can be thought of as implying the estimation of

$$
\text { Sex }_{i c}^{\star}=\beta_{0}+\beta_{1} \text { OwnDrink }_{i}+\beta_{2} \text { FemalePeerDrink }_{c}+\gamma X_{i c}+\epsilon_{i c},
$$

for male respondents, and

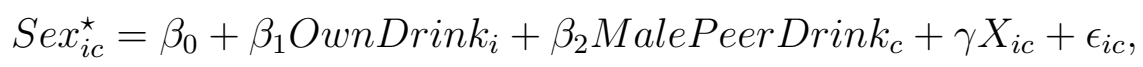

for female respondents, where $c$ denotes the cohort of individual $i$. As FemalePeerDrink $k_{c}$ and MalePeerDrink $k_{c}$ are measured at the cohort level (i.e., Add Health respondents of opposite gender within the same grade and school school as $i$ ) they do not carry the $i$ subscript. This independence from $i$ helps with the interpretation of $\hat{\beta}_{2}$ (unlike $\hat{\beta}_{1}$, still plagued by more-serious endogeneity concerns).

It is unlikely that individual $i$ 's sexual activity influences opposite-gender drinking behavior. As such, note that the estimation of (2) and (3) does not suffer to the same degree from the standard reflection problem that can challenge the interpretation of peer effects (e.g., Manski (1993), Manski (2000)). First, I consider the influence of one peer's attribute (i.e., alcohol use) on a different behavior (i.e., sexual activity) and not, for example, the effect of

to the same question, 4) the average number of days in a week that the individual reports being drunk, and 5) the average number of days in a week that the individual consumes "five or more drinks in a row." This fifth alternative is particularly attractive as it does not depend on the respondent's own determination of drunkenness, which may introduce a source of variation that could result in imprecision or bias. These measures account for alternatives I report below as OwnDrink. In both continuous measures of drinking behavior the responses come in the following form: "every day or almost every day," "3 to 5 days a week," "1 or 2 days a week," "2 or 3 days a month," "once a month or less (3-12 times in the past 12 months)," or "1 or 2 days in the past 12 months." As such, I define OwnDrink in these cases as the implied average number of days in one week.

${ }^{7}$ This and related issues are discussed further in Section 5.4 below.

${ }^{8}$ See Evans, Oates and Schwab (1992) for additional discussion. For a clever use of the friendship information see Babcock (2008), where broad cohort "connectedness" is linked to educational outcomes.

${ }^{9}$ As opposite-gender peers are of particular interest to the analysis, the sample size also reflects that I have dropped all respondents who have no same-grade, same-school contemporaries of the opposite gender within the In-Home Survey. 
peer sexual behavior on one's own sexual behavior or the effect of peer alcohol consumption on one's own alcohol consumption. Relative to standard peer-effect settings, reflection is also likely to be mitigated in this case as the peer group to which I am allowing $i$ to respond is not a simple aggregation of the behavior of other $j \neq i$ individuals in the model, but that of opposite-gender individuals who are outside of the model. That is, given gender-specific reference groups (and specifications run separately by gender) there is no error term through which the path from $i$ 's sexual behavior can transmit back to peer drinking.

\subsection{Control variables}

In primitive specifications (including only age and grade-level fixed effects in the model), female adolescents can be up to 25 percent more likely to be sexually active in where their male classmates are consuming alcohol. While I am focusing on the possible effect of opposite-gender peers, I wish to capture individual and school characteristics that have been used in previous analysis or may otherwise be expected to explain variation in sexual activity. Included in $X_{i c}$ are race (i.e., black, Asian, Hispanic, other), parent education (i.e., indicator variables for less-than high school, high school, some college, bachelor, graduate/professional), and religious participation (i.e., indicator variables for weekly attendance, monthly attendance, some attendance), academic performance (i.e., grade-point average across the four most-recent classes in English, mathematics, history or social studies, and science), and county-level measures of the proportion urban, proportion rural, and unemployment rate.

We also allow sexual activity to vary with respondents' stated beliefs regarding "ideal romantic relationships," exploiting a series of questions that has them consider the component parts of such a relationship were they to have one in the next year. Specifically, I allow a level shift in the propensity for sexual activity by whether sex is included as part of this ideal. To the extent such views are generally held within schools, including such indicators in the model will work against attributing to peer drinking what may be spuriously explained by simple variation in social norms. ${ }^{10}$ For brevity, results are not shown without the inclusion of these controls. However, models with controls yield the most conservative estimates on key variables of interest.

\section{Results}

Here, I first consider some baseline specifications separately for each gender across the five alternative measures of drinking behavior. Even though the within-school design (which I subsequently present in Section 4.2) may be the preferred design, I begin by reporting the results of both pooled and fixed-effect specifications. As part of a sensitivity analysis, presented in Section 4.3, I will build a case for considering that opposite-gender peer alcohol matters to sexuality by also considering the drinking behavior of same-gender peers, individuals' sexual orientations (to the extent permitted in the Add Health survey design), and

\footnotetext{
${ }^{10}$ Made evident in the summary statistics of Table 2 are the significant gender differences in responses to this question. In particular, 35 percent of girls are inclined to include "We would have sex" among the things that would happen in the perfect relationship, while 54 percent of boys include the same.
} 
other anti-social peer behaviors. For brevity, however, I will also address these as part of a separate discussion of sensitivity analyses.

\subsection{Baseline specifications}

Results of discrete-choice models of the form in (2) or (3) are reported separately for male and female respondents in tables 4 and 5, respectively. Given the discrete nature of the dependent variable, estimated logit coefficients are reported. To assist with interpretation, in brackets I also report the estimated coefficients from comparable linear-probability models for the key variable of interest.

\subsubsection{OwnDrink}

Across all specifications, the expected relationship between one's own drinking and a higher incidence of sexual intercourse is evident. From Column (1) of Table 4, boys reporting to have consumed alcohol within twelve months of the interview date have a predicted likelihood of reporting to have had sexual intercourse of .321, compared to a likelihood of .171 for those who have not consumed alcohol. Column (2) implies a larger difference in the predicted probabilities of being sexually active - .375 for drinkers versus .189 for non-drinkers - likely explained by the more intense alcohol consumption (i.e., having drunk "until very, very high"). Column (3) again suggests a slight increase in this separation, where more-regular drinking patterns are captured in an indicator for having drunk "until very, very high" monthly within the last year. These results are similar in the female population, with the simple measure of drinking (from Column 1 of Table 5) implying a 19 percentage point increase in the probability of engaging in sexual intercourse (over 16.2 percent) and small increases again for the additional information in the specifications of columns (2) and (3).

In the last two columns of Table 4, the fourth and fifth alternative measures of drinking behavior are employed. In both cases, OwnDrink is entered with a quadratic term, allowing for movement in the data that is missed with more blunt associations. This fits the data in both male and female samples, where Sex is quadratic in OwnDrink, with sexual activity becoming marginally less likely at higher-intensity drinking. ${ }^{11}$ Again, patterns exhibited in the female sample of Table 5 are similar.

While these relationships are to be considered with some caution due to the potential simultaneity of alcohol consumption and sexual activity, these results point to the potential for the intensity of consumption to be considered in explaining the link. This is seen in two dimensions, both across alternative measures of alcohol consumption (i.e., intensity increasing from column to column within each table) and in the continuous measures of consumption (i.e., in columns 4 and 5).

\subsubsection{PeerDrink}

At this point I wish to discuss the key relationship of interest, the influence of oppositegender PeerDrink on sexual activity. Immediately evident, though, I find that the alcohol

\footnotetext{
${ }^{11}$ The inflection points fall within the sample data (i.e., roughly 3 days per week) although such drinking intensities are rare within the sample of respondents.
} 
consumption of female peers (i.e., FemalePeerDrink in Table 4) does not explain the sexual activity of male adolescents. In male samples, across all measured drinking intensities of female peers, point estimates are small and inconsistent in sign. Thus, there is little statistical justification to consider such a relationship economically meaningful and I conclude that female drinking behaviors are not contributing to male sexual activity, or that they contribute only through the effect of a male's own drinking behavior.

That said, there is a very different story suggested by the empirical regularity revealed by the analysis in the female sample of respondents, in Table 5. First, note that point estimates across alternative measures of MalePeerDrink are uniformly positive, consistent with the drinking of male peers increasing the likelihoods that female adolescents report having engaged in sexual intercourse. However, estimates relying on the less-intense alcohol measures (e.g., columns 1 through 3), standard confidence intervals include zero. As the variation in MalePeerDrink is contributed to by multiple peers, this may suggest that in a blunt pass at capturing alcohol consumption, the influence of any drinking peer(s) is mitigated by that of any non-drinking peer(s). Alternatively, this may simply reflect that there are no substantive behavioral responses to such casual drinking (e.g., a peer drank alcohol, even once, within the last year).

Turning to measures that better discriminate the alcohol-related behavior of peers reveals a very different story. In fact, adopting continuous measures of peers' drinking intensities "Days in week drinks until very, very high" and "Days in week had 5 or more drinks" - reveals a strong and statistically significant influence of MalePeerDrink on female sexual activity. From the estimates of Column (4), across the inner-quartile range of MalePeerDrink (i.e., .05 days weekly to .35 days weekly), female sexual activity increases 4.8 percent, from a predicted probability of .311 to a predicted probability of .326 . From the $10^{\text {th }}$ to $90^{\text {th }}$ percentile of MalePeerDrink (i.e., .003 days weekly to .50 days weekly), female sexual activity increases 7.8 percent, from a predicted probability of .309 to a predicted probability of .333. In the sample of females considered, this equates with roughly 142 additional females expected to be engaging in sexual activity across the inner-quartile range of MalePeerDrink. Similar patterns are also evident in Column (5), where drinking patterns are much less subjectively revealed, which suggests that the underlying pattern is robust to the subjectivity afforded to respondents in their consideration of what constitutes "very, very high" on alcohol. The similarity is also consistent with there being little systematic difference between the frequency of perceived drunkenness (i.e., days being "very, very high" in a typical week) and the frequency of consuming "five or more" alcoholic drinks in a typical week. Overall, the data are clearly revealing a sensitivity in female adolescent sexuality to the drinking intensity of their male peers. ${ }^{12}$

In no case do I find that interacting PeerDrink and OwnDrink is significant. Although point estimates of this relationship are positive, there is no meaningful complementarity evident between one's own drinking and the drinking behavior of peers in driving one's proclivity toward sexual activity.

\footnotetext{
${ }^{12}$ In neither Column (4) or Column (5) do I find any extra explanatory power in including a quadratic in MalePeerDrink. I therefore exclude the quadratic from the model.
} 


\subsubsection{Other covariates}

Before continuing to the comparable model with school-fixed effects, I report briefly on some of the movement in Sex explained by other covariates. Given the detailed set of controls adopted, several additional regularities appear in the data that are new to the literature. For example, controlling for attendance in religious services - and not just an indicator for religious affiliation - reveals a decreasing probability of sexual intercourse occurring with more-frequent attendance. Using estimated coefficients from the fifth columns of tables 4 and 5, regular weekly attendance in religious services is associated with a 16 percent decline in the predicted probability of a male having sexual intercourse (i.e., from .256 to .215) and a 21.4 percent decline for females (i.e., from .276 to .217). Academic performance is also predictive of less sexual activity, with the difference between a 2.0 GPA and a 4.0 GPA associated with a 27.8 percent decline in the probability of having intercourse for males (i.e., from .259 to .187) and 35.9 percent for females (i.e., from .295 to .189). Among previously established results, I also find a higher incidence of sexual intercourse occurring for black and Hispanic/Latino adolescents, in higher grade levels and for students with parents who report lower levels of education.

With respect to whether respondents include "We would have sex" in their ideal romantic relationships, there is considerable difference in sexual activity. For example, from Column (5) of Table 5, females who do not claim "We would have sex" among the events in their ideal romantic relationship have a predicted probability of sexual activity equal to .155, while those who do include "We would have sex" have a propensity to be sexually active of roughly .50 - more than a threefold increase. A similar difference is seen in male respondents. As is the case with all potentially endogenous variables in this exercise, dropping this variable from the analysis only increases the significance of PeerDrink variables, both statistically and economically. ${ }^{13}$

\subsection{Controlling for school-level unobserved heterogeneity}

Recall the earlier discussion of the estimated relationship between OwnDrink $k_{i}$ and one's own sexual activity, where one might be concerned that the estimated coefficient is biased (upward) due to the omission of unobserved individual heterogeneity that systematically drives both OwnDrink and $_{i} \operatorname{Sex}_{i c}$. This is the standard challenge to existing analysis of the effect of one's own drinking behavior on one's own sexual activity. However, as MalePeerDrink $k_{c}$ is arguably exogenous to the female Sex $i c$ being modeled in (3), a similar objection should not be raised. That said, one should not rule out that the estimated coef-

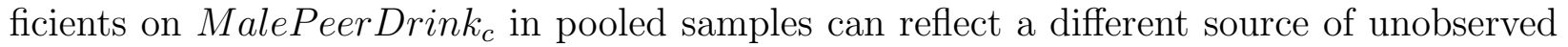
heterogeneity.

In particular, the type of unobserved heterogeneity that would defeat the pooled-sample estimates is that which would cause males in particular grades within particular schools to drink while also causing females in those same grades and schools to engage in sexual intercourse (and that was not already absorbed by the female's own drinking patterns, being held constant by OwnDrink $k_{i}$. While this already implies a fairly particular source of variation,

\footnotetext{
${ }^{13}$ For example, the point estimate on MalePeerDrink in Column (5) of Table 5 increases from .26 to .49 when only grade and age level dummies are included in the model (with a standard error of .125).
} 
not to mention that age fixed effects are also included, one can speak to any concern that such a bias exists by re-estimating the models while absorbing school-level unobserved heterogeneity into the error structure. In tables 6 and 7 school fixed effects are included in the models, respectively, which will control both for unobserved characteristics that might be shared by adolescents within schools and for any influence of the school itself on the behavior of these youth (e.g., the "contextual effects" of Manski (1993)). Using school-level fixed effects should eliminate a majority of group unobservables (e.g., Hoxby (2000), Hanushek et al. (2003)), and if families choose schools based on time-invariant school characteristics, controlling for school fixed effects controls for the main source of selection into schools. As

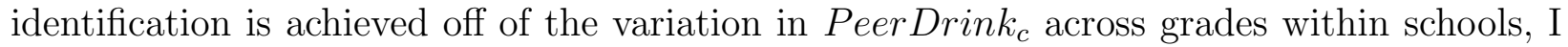
drop the grade-level fixed effects and capture level differences in sexual activity with the age fixed effects.

As a very strong test of the robustness of the patterns already identified, the baseline results from pooled samples are indeed robust to the inclusion of school-level fixed effects, which eliminates a key source of omitted variation in the baseline specifications as an explanation for the empirical regularity above. Furthermore, within-school considerations now suggest that female Sex systematically varies with even the blunt measures of MalePeerDrink in columns (1) through (3). Were the prior results driven by the type of unobserved heterogeneity described above or by some non-random sorting, one would expect an attenuation of the coefficient estimates with such controls added to the model. Clearly, then, females within individual schools with alcohol-consuming opposite-gender peers reveal a higher proclivity toward sexual activity. Likewise, accounting for unobserved school-specific heterogeneity does not change that there is no explanatory power in FemalePeerDrink in explaining male sexual activity.

I've reported estimated logit coefficients in Table 7. However, were one to consider marginal changes in Sex with changes in MalePeerDrink in an OLS framework (unreported), Column (5) would imply an underlying marginal effect of .049 - an economically meaningful change in one's proclivity to engage in sexual activity with a change in the drinking behavior of male peers. ${ }^{14}$ This is similar to the estimated marginal effect reported in the pooled sample of Table 5 .

\subsection{Sensitivity analysis}

At this point, it pays to consider that the above analysis may not have estimated the magnitude of any causal role for male alcohol consumption in explaining female sexual activity. Yet, it is a fairly peculiar story required in order to explain the patterns in the data without employing that MalePeerDrink may well cause female Sex. Even so, some scope remains for considering confounding factors insofar as attributes of the female subjects' environments are jointly determining Sex and MalePeerDrink. For example, if data do not allow one to fully control for local attributes, one could observe the behavior of student $i$ "changing" with that of $i$ 's opposite-gender peers even in the absence of a true peer effect, simply because

\footnotetext{
${ }^{14}$ Recall that it is not possible to estimate a true marginal effect from the conditional fixed-effect model since one cannot estimate the probability of a positive outcome at the individual level.
} 
some unobserved local attributes are systematically driving both. ${ }^{15}$ Below, I discuss a series of additional robustness tests, which I then follow with some concluding remarks.

As a matter of brevity, I will report only the key variables of interest, noting that there are no significant differences in the estimated influence of control variables from the baseline equations. In no specification on the male sample do significant patterns emerge. Thus, I will also refrain from reporting additional results from the sample of male adolescents.

\subsubsection{Does female-peer drinking have a similar effect?}

Even though the causal estimate may escape the above analysis, one might propose that the effect of MalePeerDrink on female Sex would only be interpretable as causal to the extent that the drinking of same-gender peers did not similarly contributed to female sexual activity. To find that female peers have similar "influence" on female sex, for example, would cast doubt on any attempt to unpack the alcohol-leading-to-sex relationship further. As a falsification exercise, then, I include just such a measure, which allows one to rule out that the opposite-gender result is simply a proxy for the broader peer environment the individual is found in. Table 8 includes this measure for both pooled and within-school specifications, with the strong suggestion that there is something quite unique in the nature of MalePeerDrink's influence on female sexual activity. In short, the comparable FemalePeerDrink does not contribute to explaining female sexual activity in either pooled samples or in models that exploit only within-school variation. In particular, across all measures of drinking behavior, point estimates are inconsistent in sign and never fall outside of standard confidence intervals.

In a different context, Clark and Loheac (2007) look across cohorts and find that in alcohol consumption, both boys and girls follow the behavior of boys from older cohorts, and that female cohorts do not influence younger cohorts of either boys or girls. While speaking to a different question, girls' sexual activity being responsive to male behaviors and not to female behaviors is arguably consistent with the asymmetry of Clark and Loheac (2007), and may be the subject of future research.

\subsubsection{Are there differentials around sexual orientation?}

While Add Health does not directly inquire about the sexual orientation of survey respondents, the intersection of two survey questions may overlap with such an orientation in a way that is worth considering - the questions being "Have you ever had a romantic attraction to a female?" and "Have you ever had a romantic attraction to a male?" I define homosexual males (female) as those males (females) who respond "No" ("Yes") to the first question and "Yes" ("No") to the second question. I then interact this variable with PeerDrink, anticipating that the measured influence of opposite-gender drinking will attenuate for those with homosexual preferences.

In short, while the differential is slight and does not allow one to conclude that there is a significant difference in the peer effect by our measure of sexual orientation, the point

\footnotetext{
${ }^{15} \mathrm{~A}$ second possibility exists, although I suspect does not much matter to our particular context. It is possible that $i$ and $i$ 's opposite-gender peers decide to attend the same school-grade because they like the same local attribute, which in turn influence their behaviors in the way required, or because they both like to be near individuals with similar characteristics. In these cases, the supposed effect of peers would instead be the result of sorting according to these attributes.
} 
estimate on the interaction (in Table 9) is of the expected sign and large. Also, the point estimates on the underlying effect of MalePeerDrink tend to increase. Of course, that the number of individuals claiming such orientation is small (i.e., 0.8 percent of males and 1.43 percent of females) may contribute to the imprecise estimates and a better measure of homosexuality may well have revealed more-distinct behavior.

\subsubsection{Do other anti-social male-peer behaviors have similar effect?}

To rule out that the inclusion of male drinking is merely a proxy for a male-peer "type" rather than for actual variation that relates to their alcohol-induced behaviors (e.g., lowered inhibitions), I analyze an alternative measure of peers' anti-social behaviors for additional evidence that the documented relationship is actually something alcohol related. In particular, I consider the reported tobacco use of opposite-gender peers. In so doing, I find that point estimates are generally positive but not different from zero. Ultimately, there is no ability to claim that there is a significant influence of male-peer tobacco use on female sexual activity. Clearly, the inclusion of MalePeerDrink is not merely separating out certain peer "types" in the way that any anti-social measure of peer behavior would. In other words, female interaction with general anti-social behavior in their male peers is not driving the pattern uncovered. Moreover, while the inclusion of OwnSmoke does tend to attenuate the relationship between OwnDrink and Sex (as expected), the relationship between MalePeerDrink and female sex survives the inclusion of both own and male-peer tobacco use. These results are reported in Table 10.

\section{Discussion}

Before concluding, there are several outstanding issues that can be briefly addressed, each being less about the robustness of the above result and more about the extent to which one can learn about other patterns. Specifically, I will consider whether there are discernible grade-level effects in the data, whether peers of different ages matter to sexual activity, and whether the nature of the sexual experience is different in alcohol-rich environments.

\subsection{Grade-level heterogeneity}

While not so much a question of robustness, one might consider the extent to which the pattern identified is generally held across grade levels. Doing so, I have no strong prior as to where the measured influence of peers should be larger. On one hand, it would seem reasonable to anticipate that if younger students are more impressionable (even though, in levels, they are less likely to participate) they may be more-strongly influenced by drinking peers and thus appear more responsive at the margin. Yet, the young may be farther from the margin of engaging in sexual relationships and therefore less responsive to any encouraging influence. In ancillary analysis, I interacted MalePeerDrink with the respondent's grade level while controlling for a linear relationship in grade-level itself. The point estimates suggest that the influence of male peers attenuates with grade level. However, estimates are imprecise and one could reasonably conclude that there are no significant differences in the marginal influence of PeerDrink across grade levels. 


\subsection{Does the drinking of older male peers matter?}

There is some evidence that females are more sexually active where the drinking of male peers in lower grades is higher. However, this pattern is only evident in across-school specifications, and there is no indication that such patterns exist within schools. Even though I acknowledge that power is somewhat limited as the sample size can fall off - with first and last grades within schools subject to being dropped from the analysis - I conclude that there are no significant across-grade effects. Re-running similar specifications on male samples reveals no patterns in either pooled or within-school specifications.

\subsection{Are there indications of sexual aggression?}

It is reasonable to consider that any sexual intercourse facilitated in any way by alcohol may also be a different type of experience. That is, the nature of sexual relations may also change in the presence of alcohol. I find no evidence that there is a decrease in the use of contraception where male peers consume alcohol. I also find no direct evidence that females are significantly more likely to be forced to have sexual intercourse where male peers consume alcohol. ${ }^{16}$ That is, while point estimates are positive (and can be large), any increase in forced sex associated with MalePeerDrink is not statistically significant. As I am focussing here on the influence of opposite-gender peers, this lack of evidence could be seen as a contrast (or a limit) to existing results in the literature that suggest that the nature of sex might change with alcohol (e.g., Markowitz, Kaestner and Grossman (2005), Grossman and Markowitz (2005)). Indirectly, there is at least a suggestion that the nature of sexual relations changes with alcohol, as male adolescents who themselves drink alcohol are more likely to report having forced someone to have sexual intercourse. Yet, such specifications reintroduce a more-severe endogeneity concern and the causal implications of such a pattern are not clear. ${ }^{17}$ This may prove to be a fruitful area for future research.

\subsection{Alternative identification strategies?}

While the empirical regularities above allow for a causal interpretation, further disentangling exogenous variation in MalePeerDrink would be essential in recovering an unbiased estimate of the underlying causal influence of male-peer drinking on female sexual activity. In this respect, however, the IV strategies attempted in the literature thus far (e.g., Rees, Argys and Averett (2001), Sen (2002)) come with the same concerns raised in Rashad and Kaestner (2004). Regardless, such sources of variation yield a weak first stage when used to instrument for MalePeerDrink. ${ }^{18}$ (The point estimate on MalePeerDrink does increase in magnitude, but there is insufficient power to draw conclusions from this exercise.) Within

\footnotetext{
${ }^{16}$ Specifically, females were asked, "Were you ever physically forced to have sexual intercourse against your will?" while males were asked, "Did you ever physically force someone to have sexual intercourse against her will?"

${ }^{17}$ Again, see Rees, Argys and Averett (2001), Sen (2002), and Rashad and Kaestner (2004) for related discussions.

${ }^{18}$ Recall the set of possible instrumental variables: whether the state requires alcohol and drug education, per-capita local spending on police, add per-capita state spending on police, arrests per violent crime, and arrests per crime.
} 
this framework, however, it is not clear that we don't desire a more-discriminating instrument - one that affects the drinking behavior of one gender but not the other. If so, this only emphasizes how difficult it is to find a good instrument is this framework.

There are other potential instruments that one might anticipate being brought to bear on this problem, but are problematic with respect to the required second-stage exclusion. For example, using the availability of alcohol in male-peers' homes as an instrument for MalePeerDrink should violate the required exclusion from predicting Sex directly as parents of male peers who make alcohol easily available may well be the same as provide opportunities for sexual contact to occur in their homes.

In Section 3.1, I also commented on the merits of defining the individual's relevant peer group using the friendship nominations the individual makes, the point being that this set of friends is of little benefit to recovering a causal estimate of the relationship of interest, for it confounds both friends' alcohol consumption having some influence over outcomes and the friends having been chosen in part for their alcohol consumption. Moreover, defining peers as the nominated friends and instrumenting for their alcohol consumption with that of other un-nominated classmates is likewise apt to violate the exclusion restriction as it seems unjustified to argue that the influence of classmate drinking operates only through it's influence on nominated-friend drinking and not directly.

\section{Conclusion}

With detrimental outcomes being associated with promiscuity, there remains need for us to better understand the underlying determinants of risky adolescent behaviors. Through this analysis I have aimed at better understanding the potential role of peers' alcohol use in determining the propensity for adolescent youth to engage in sexual intercourse. This is a broader perspective on what constitutes the relevant alcohol-related causes of adolescent sexual activity than has been considered in the existing literature.

In particular, this analysis has exploited the bilateral nature of sexual intercourse - that intercourse involves both a male and female participant - and has provided evidence that would be consistent with the alcohol consumption of male peers having some influence on the sexual activity of females. The analysis also points to this relationship being strongly gender dependent, as there is no evidence of female-peer drinking influencing male sexual activity.

This relationship is most evident in within-school specifications and is robust to several additional considerations. For example, the systematic patterns in female sex and male-peer drinking are shown to be distinctly different from any influence that same-gender peers may have on sexual activity. In fact, female-peer drinking is found to contribute very little to explaining female sexual activity. This suggests that the pattern is not being driven by broader cohort-level effects, but specifically through relationships that cross genders. The apparent influence of alcohol-consuming male peers is robust to controlling for general antisocial peer behaviors, which themselves fail to explain female sexual activity. Estimated coefficients on the key variables of interest also suggest that the influence of male peers attenuates in those where a homosexual preferences are indicated, conforming to one's priors in a way that builds confidence that the movements being described by the empirical models 
are reasonable. Further research into the mechanisms by which these and other behaviors are transmitted across gender lines seems warranted.

With respect to physiology, human consumption of alcohol initially serves as a stimulant, then induces feelings of relaxation and reduced anxiety, and can impair judgment, lower inhibitions, and induce mild euphoria. In considering the influence of alcohol on sexual relations, it is also worthy to note that men have a higher ability to both dilute and metabolize alcohol. ${ }^{19}$ If anything, then, this supports the prior that volume-constant alcohol consumption by males will have less influence on female sexual activity - working against the documented patterns. To the extent one anticipates that alcohol acts on sexual relations through reduced inhibitions, then, the empirical results can be interpreted as suggesting that male inhibitions may initially be a greater impediment to adolescent sexual activity than female inhibitions, ceteris paribus.

With the motivations for sexual activity being different across gender, the Add Health survey offers some opportunity to consider these motives as explanatory to this influence. In ancillary analysis, there are some indications that the mechanism at play is working in spite of certain priors respondents have about the underlying margins of importance. For example, in within-school empirical strategies, girls who "agree" or "strongly agree" with the statements, "If you had sexual intercourse, your partner would lose respect for you," "..., afterward, you would feel guilty," or "..., it would upset your mother/father," are less inclined to be sexually active, on average, and are influenced less at the margin by the presence of alcohol-consuming male peers. While not accounting for the potential that these stated positions may be influenced by sexual activity itself, this is suggestive of the influence of alcohol-consuming male peers working quite systematically on female youth - more on those who imply lower costs to sexual activity and less on those who are inclined to associate costs with sexual activity.

The data also suggests that the more agreeable girls are to the statements, "If you had sexual intercourse, it would give you a great deal of pleasure," or "..., it would relax you," the more inclined they are toward being sexually active and are more strongly influenced they are by alcohol-consuming male peers, at the margin. Although the empirical regularities suggest that the factors and interactions related to sexual activity are complex, that adolescents are following these patterns is somewhat encouraging. For example, if anticipated pleasure is driving female behavior to this extent, policy that encourages female adolescents to delay the pleasure they expect from sexual activity is a reasonable prescription. If the anticipated costs (e.g., upsetting one's mother or father) are mitigating the influence of male peers, systematically increasing such costs may lower adolescent female sexual activity.

\footnotetext{
${ }^{19}$ That is, both water content and the presence of dehydrogenase - an enzyme that breaks down alcohol - are higher in male population.
} 


\section{References}

Babcock, Philip. 2008. "From Ties to Gains? Evidence on Connectedness and Human Capital Acquisition." Journal of Human Capital, 2(4): 379-409.

Bray, Jeremy W. 2005. "Alcohol Use, Human Capital, and Wages." Journal of Labor Economics, 23(2): 279-312.

Carpenter, Christopher. 2005. "Youth Alcohol Use and Risky Sexual Behavior: Evidence from Underage Drunk Driving Laws." Journal of Health Economics, 24(3): 613-328.

Chesson, H., P. Harrison, and W.J. Kassler. 2000. "Sex Under the Influence: The Effect of Alcohol Policy on Sexually Transmitted Disease Rates in the United States." Journal of Law and Economics, 43: 215-238.

Clark, A. E., and Y. Loheac. 2007. "It Wasn't Me, It Was Them! Social Influence in Risky Behavior by Adolescents." Journal of Health Economics, 26: 2249-2258.

Dee, Thomas S. 2001. "The Effects of Minimum Legal Drinking Ages on Teen Childbearing." Journal of Human Resources, 36: 823-828.

Evans, William N., Wallace E. Oates, and Robert M. Schwab. 1992. "Measuring Peer Group Effects: A Study of Teenage Behavior." The Journal of Political Economy, 100(5): 966-991.

Grossman, Michael, and Sara Markowitz. 2005. "I Did What Last Night? Adolescent Risky Sexual Behaviors And Substance Use." Eastern Economic Journal, 31(3): 383-405.

Hanushek, E.A., J.F. Kain, J.M. Markman, and S.G. Rivkin. 2003. "Does Peer Ability Affect Student Achievement?" Journal of Applied Econometrics, 18(5): 527-544.

Heckman, James J., Rodrigo Pinto, and Hongbo Wang. 2008. "Determinants of Risk Behaviors in Early Adulthood: Interplay of Cognitive Ability, Noncognitive Skills, and Health." University of Chicago.

Hoxby, Caroline. 2000. "Peer Effects in the Classroom: Learning from Gender and Race Variation." National Bureau of Economic Research NBER Working Papers 7867.

Kling, J., J. Ludwig, and L. Katz. 2005. "Neighborhood Effects on Crime for Female and Male Youth: Evidence from a Randomized Housing Voucher Experiment." Quarterly Journal of Economics, 120(1): 87-130.

Kooreman, Peter. 2007. "Time, Money, Peers, and Parents: Some Data and Theories on Teenage Behavior." Journal of Population Economics, 20(1): 9-33.

Krauth, Brian V. 2005. "Peer Effects and Selection Effects on Smoking Among Canadian Youth." The Canadian Journal of Economics, 38(3): 735-757.

Lacruz, Ana I. Gil, Marta Gil Lacruz, and Juan Oliva Moreno. 2009. "Are Drinkers Prone To Engage In Risky Sexual Behaviors?" Departmento De Analisis Economico. 
Manski, Charles F. 1993. "Indentification of Endogenous Social Effects: The Reflection Problem." Review of Economic Studies, 60(3): 531-542.

Manski, Charles F. 2000. "Economic Analysis of Social Interactions." Journal of Economic Perspectives, 14(3): 115-136.

Markowitz, Sara, Robert Kaestner, and Michael Grossman. 2005. "An Investigation of the Effects of Alcohol Consumption and Alcohol Policies on Youth Risky Sexual Behaviors." American Economic Review Papers and Proceedings, 95(2): 263-266.

Mocan, H. Naci, and Erdal Tekin. 2005. "Drug Use and Juvenile Crime: Evidence from a Panel of Siblings and Twins." In Economics of Substance Use: Individual Behavior, Social Interactions, Markets, and Politics. , ed. Bjorn Lindgren and Michael Grossman, 91-120. Amsterdam: Elsevier.

Mocan, H. Naci, and Erdal Tekin. 2006. "Guns and Juvenile Crime." Journal of Law and Economics, XLIX: 507-531.

Rashad, Inas, and Robert Kaestner. 2004. "Teenage Sex, Drugs and Alcohol Use: Problems Identifying the Cause of Risky Behaviors." Journal of Health Economics, 23: 493-503.

Rees, Daniel I., Laura M. Argys, and Susan L. Averett. 2001. "New Evidence on the Relationship Between Substance Use and Adolescent Sexual Behavior." Journal of Health Economics, 20: 835-845.

Renna, Francesco. 2007. "The Economic Cost of Teen Drinking: Late Graduation and Lowered Earnings." Health Economics, 16(4): 407-419.

Sabia, Joseph J., and Daniel I. Rees. 2009. "The Price of Promiscuity: Does the Number of Sex Partners Affect School Attainment?" University of Colorado - Denver Working Paper.

Sen, B. 2002. "Does Alcohol-Use Increase the Risk of Sexual Intercourse Among Adolescents? Evidence from the NLSY97." Journal of Health Economics, 21: 1085-1093.

Sen, Bisakha. 2003. "Can Beer Taxes Affect Teen Pregnancy? Evidence Based on Teen Abortion Rates and Birth Rates." Southern Economic Journal, 70(2): 328-343.

Soetevent, A.R., and Peter Kooreman. 2006. "A Discrete Choice Model with Social Interactions with an Application to High School Teen Behavior." Journal of Applied Econometrics, 22(3): 599-624.

Tekin, Erdal, and Sara Markowitz. 2008. "The Effects of Suicidal Behavior on Productive Activities of Young Adults." Southern Economic Journal, 75(2): 300-331. 
Table 1: Stated views of sexual activity

\begin{tabular}{|c|c|c|c|c|c|c|}
\hline & $\begin{array}{l}\text { Strongly } \\
\text { Disagree }\end{array}$ & Disagree & $\begin{array}{c}\text { Neither Agree } \\
\text { or Disagree }\end{array}$ & Agree & $\begin{array}{l}\text { Strongly } \\
\text { Agree }\end{array}$ & $\begin{array}{l}\text { Log-Odds }^{a} \\
\text { (std.dev.) }\end{array}$ \\
\hline \multicolumn{7}{|c|}{ If you had sexual intercourse, your friends would respect you more. } \\
\hline Male & 0.13 & 0.27 & 0.39 & 0.16 & 0.05 & \multirow{2}{*}{$\begin{array}{c}1.22^{* * *} \\
(0.03)\end{array}$} \\
\hline Female & 0.30 & 0.38 & 0.27 & 0.03 & 0.02 & \\
\hline \multicolumn{7}{|c|}{... your partner would lose respect for you. } \\
\hline Male & 0.14 & 0.40 & 0.33 & 0.09 & 0.04 & \multirow{2}{*}{$\begin{array}{c}-0.22^{* * *} \\
(0.03)\end{array}$} \\
\hline Female & 0.17 & 0.31 & 0.31 & 0.14 & 0.07 & \\
\hline \multicolumn{7}{|c|}{... afterward, you would feel guilty. } \\
\hline Male & 0.12 & 0.31 & 0.30 & 0.16 & 0.10 & \multirow{2}{*}{$\begin{array}{c}-0.69 * * * \\
(0.03)\end{array}$} \\
\hline Female & 0.08 & 0.22 & 0.25 & 0.23 & 0.22 & \\
\hline \multicolumn{7}{|c|}{... it would upset your mother/father. } \\
\hline Male & 0.04 & 0.13 & 0.23 & 0.28 & 0.31 & \multirow{2}{*}{$\begin{array}{c}-0.86^{* * *} \\
(0.03)\end{array}$} \\
\hline Female & 0.03 & 0.07 & 0.13 & 0.26 & 0.52 & \\
\hline \multicolumn{7}{|c|}{.. it would give you a great deal of physical pleasure. } \\
\hline Male & 0.03 & 0.07 & 0.29 & 0.40 & 0.22 & \multirow{2}{*}{$\begin{array}{c}1.29^{* * *} \\
(0.04)\end{array}$} \\
\hline $\begin{array}{l}\text { Female } \\
\text {.. it woul }\end{array}$ & 0.09 & 0.14 & 0.48 & 0.23 & 0.06 & \\
\hline Male & 0.04 & 0.10 & 0.42 & 0.33 & 0.12 & \multirow{2}{*}{$\begin{array}{c}1.30^{* * *} \\
(0.04)\end{array}$} \\
\hline Female & 0.11 & 0.20 & 0.53 & 0.13 & 0.03 & \\
\hline \multicolumn{7}{|c|}{... it would make you more attractive to the opposite sex. } \\
\hline Male & 0.11 & 0.28 & 0.45 & 0.11 & 0.05 & \multirow{2}{*}{$\begin{array}{c}1.14^{* * *} \\
(0.03)\end{array}$} \\
\hline Female & 0.30 & 0.35 & 0.29 & 0.04 & 0.01 & \\
\hline \multicolumn{7}{|c|}{... you would feel less lonely. } \\
\hline Male & 0.09 & 0.27 & 0.40 & 0.20 & 0.05 & \multirow{2}{*}{$\begin{array}{c}1.25^{* * *} \\
(0.03)\end{array}$} \\
\hline Female & 0.28 & 0.37 & 0.27 & 0.07 & 0.01 & \\
\hline
\end{tabular}

*** $\mathrm{p}<0.01,{ }^{* *} \mathrm{p}<0.05,{ }^{*} \mathrm{p}<0.1^{a}$ Estimated ordered log-odds regression coefficients on a 'male' indicator variable from separate ordered-logit specifications of each survey question $(n=12,128$, survey respondents aged fifteen or above). Survey responses are coded from "Strongly Disagree" $=1$ to "Strongly Agree" = 5. The ordered-logit regression coefficient captures the expected change in the response variable level (in the ordered log-odds scale) that can be associated with a one unit increase in the predictor ( 
Table 2: Summary statistics

\begin{tabular}{|c|c|c|c|c|}
\hline & \multicolumn{2}{|c|}{ Male } & \multicolumn{2}{|c|}{ Female } \\
\hline & Mean & StdDev & Mean & StdDev \\
\hline Sex in the last year, Grade 7 & 0.08 & 0.27 & 0.06 & 0.23 \\
\hline Sex in the last year, Grade 8 & 0.16 & 0.37 & 0.15 & 0.36 \\
\hline Sex in the last year, Grade 9 & 0.24 & 0.43 & 0.26 & 0.44 \\
\hline Sex in the last year, Grade 10 & 0.34 & 0.47 & 0.35 & 0.48 \\
\hline Sex in the last year, Grade 11 & 0.45 & 0.50 & 0.45 & 0.50 \\
\hline Sex in the last year, Grade 12 & 0.51 & 0.50 & 0.55 & 0.50 \\
\hline Age (at interview) & 15.73 & 1.71 & 15.56 & 1.72 \\
\hline White & 0.51 & 0.50 & 0.51 & 0.50 \\
\hline Black & 0.21 & 0.41 & 0.23 & 0.42 \\
\hline Asian/Pacific & 0.08 & 0.27 & 0.07 & 0.25 \\
\hline Hispanic/Latino & 0.17 & 0.38 & 0.16 & 0.37 \\
\hline Other Non-White & 0.01 & 0.10 & 0.01 & 0.10 \\
\hline GPA in four core classes & 2.47 & 0.99 & 2.75 & 0.93 \\
\hline Parent Educ: Less than high school & 0.13 & 0.34 & 0.14 & 0.35 \\
\hline Parent Educ: High school & 0.25 & 0.43 & 0.26 & 0.44 \\
\hline Parent Educ: Some college & 0.26 & 0.44 & 0.25 & 0.43 \\
\hline Parent Educ: College & 0.12 & 0.33 & 0.12 & 0.32 \\
\hline Parent Educ: Graduate/Professional & 0.08 & 0.26 & 0.08 & 0.27 \\
\hline Religious attendance: Weekly & 0.37 & 0.48 & 0.41 & 0.49 \\
\hline Religious attendance: Monthly & 0.20 & 0.40 & 0.20 & 0.40 \\
\hline Religious attendance: Some & 0.18 & 0.38 & 0.18 & 0.39 \\
\hline Sex included in ideal relationship & 0.54 & 0.50 & 0.35 & 0.48 \\
\hline Proportion urban (county) & 0.65 & 0.39 & 0.65 & 0.39 \\
\hline Proportion rural (county) & 0.24 & 0.27 & 0.24 & 0.27 \\
\hline Unemployment rate (county) & 0.07 & 0.02 & 0.07 & 0.02 \\
\hline Grade 7 & 0.13 & 0.33 & 0.13 & 0.34 \\
\hline Grade 8 & 0.13 & 0.34 & 0.13 & 0.34 \\
\hline Grade 9 & 0.18 & 0.38 & 0.18 & 0.38 \\
\hline Grade 10 & 0.20 & 0.40 & 0.19 & 0.39 \\
\hline Grade 11 & 0.20 & 0.40 & 0.19 & 0.39 \\
\hline Grade 12 & 0.16 & 0.37 & 0.17 & 0.38 \\
\hline Observations & \multicolumn{2}{|c|}{9,105} & \multicolumn{2}{|c|}{9,482} \\
\hline
\end{tabular}


Male $(\mathrm{n}=9,105)$

Over the past 12 months:

Did drink alcohol

Did drink alcohol until very, very high

Did drink alcohol until very, very high monthly

Number of days each week drank alcohol until very, very high

Number of days each week had 5 or more alcoholic drinks

Female $(\mathrm{n}=9,482)$

Over the past 12 months:

Did drink alcohol

Did drink alcohol until very, very high

Did drink alcohol until very, very high monthly

Number of days each week drank alcohol until very, very high

Number of days each week had 5 or more alcoholic drinks

Mean StdDev Min Max

$\begin{array}{llll}0.48 & 0.50 & 0 & 1 \\ 0.30 & 0.46 & 0 & 1 \\ 0.12 & 0.33 & 0 & 1 \\ 0.24 & 0.84 & 0 & 6 \\ 0.29 & 0.93 & 0 & 6\end{array}$

\begin{tabular}{cccc} 
Mean & StdDev & Min & Max \\
\hline 0.47 & 0.50 & 0 & 1 \\
0.27 & 0.44 & 0 & 1 \\
0.08 & 0.27 & 0 & 1 \\
0.13 & 0.56 & 0 & 6 \\
0.15 & 0.65 & 0 & 6
\end{tabular}

Nol 
Table 4: Male sexual activity and the drinking behavior of their female peers

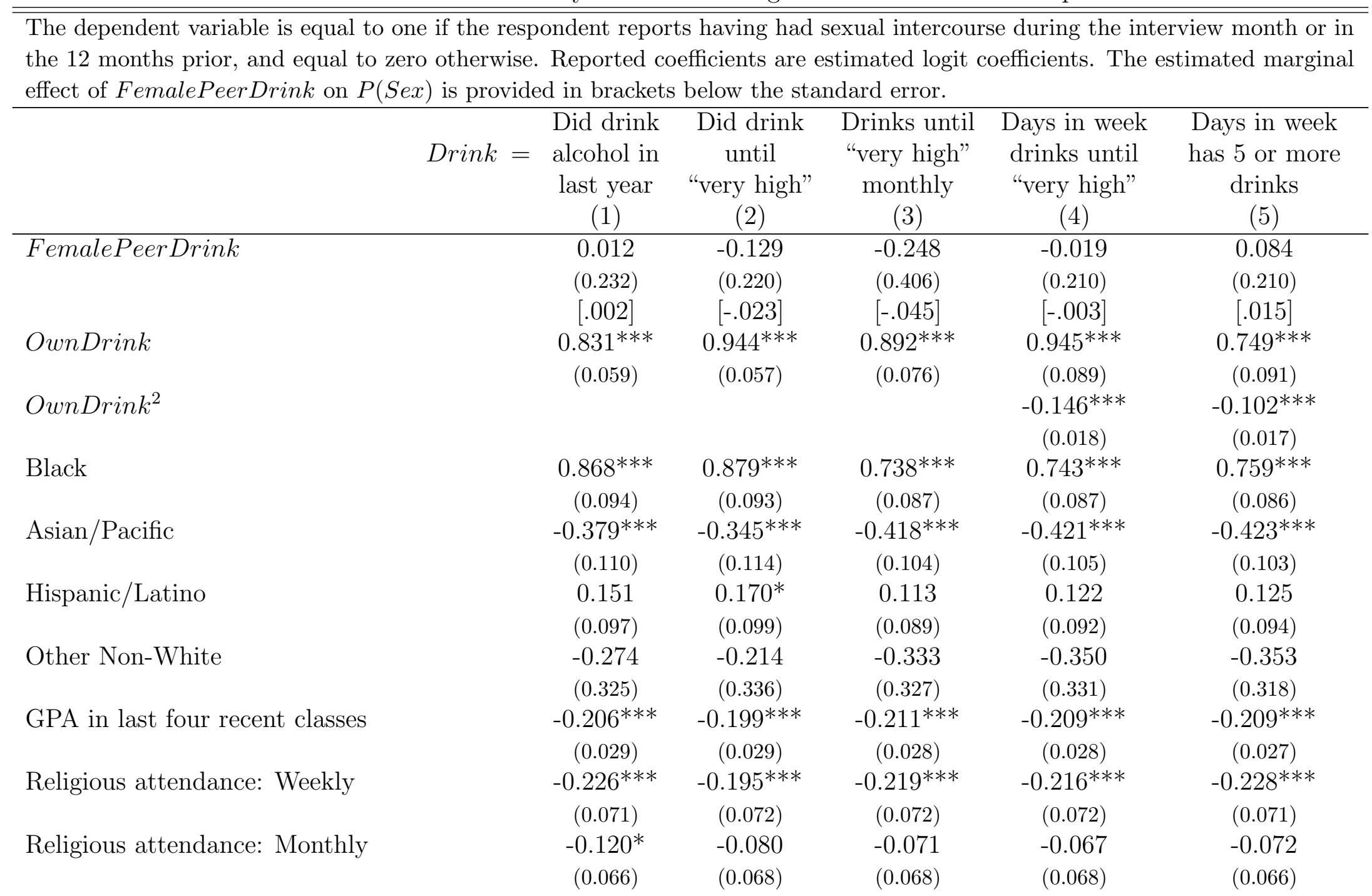


Table 4: Continued...

\begin{tabular}{|c|c|c|c|c|c|c|}
\hline & Drink $=$ & $\begin{array}{l}\text { Did drink } \\
\text { alcohol in } \\
\text { last year } \\
(1)\end{array}$ & $\begin{array}{l}\text { Did drink } \\
\text { until } \\
\text { "very high" } \\
(2)\end{array}$ & $\begin{array}{l}\text { Drinks until } \\
\text { "very high" } \\
\text { monthly } \\
(3)\end{array}$ & $\begin{array}{l}\text { Days in week } \\
\text { drinks until } \\
\text { "very high" } \\
(4)\end{array}$ & $\begin{array}{c}\text { Days in week } \\
\text { has } 5 \text { or more } \\
\text { drinks } \\
(5)\end{array}$ \\
\hline Religious attendance: Some & & -0.075 & -0.075 & -0.020 & -0.014 & -0.034 \\
\hline & & $(0.074)$ & $(0.076)$ & $(0.073)$ & $(0.073)$ & $(0.074)$ \\
\hline Sex included in ideal relationship & & $\begin{array}{c}1.618^{* * *} \\
(0.053)\end{array}$ & $\begin{array}{c}1.581^{* * *} \\
(0.053)\end{array}$ & $\begin{array}{c}1.662^{* * *} \\
(0.055)\end{array}$ & $\begin{array}{c}1.661^{* * *} \\
(0.055)\end{array}$ & $\begin{array}{c}1.663^{* * *} \\
(0.054)\end{array}$ \\
\hline Constant & & $\begin{array}{c}-3.696^{* * *} \\
(0.419)\end{array}$ & $\begin{array}{c}-3.616^{* * *} \\
(0.411)\end{array}$ & $\begin{array}{c}-3.437^{* * *} \\
(0.402)\end{array}$ & $\begin{array}{c}-3.456^{* * *} \\
(0.406)\end{array}$ & $\begin{array}{c}-3.483^{* * *} \\
(0.414)\end{array}$ \\
\hline Observations & & 9105 & 9105 & 9105 & 9105 & 9105 \\
\hline
\end{tabular}

Standard errors in parentheses, corrected for clustering at the school level; ${ }^{* * *} \mathrm{p}<0.01,{ }^{* *} \mathrm{p}<0.05,{ }^{*} \mathrm{p}<0.1$. All specifications include grade and age fixed effects, parent education (i.e., indicator variables for high school, some college, bachelor, graduate/professional), and county-level measures of the proportion urban, proportion rural, and unemployment rate. 
Table 5: Female sexual activity and the drinking behavior of their male peers

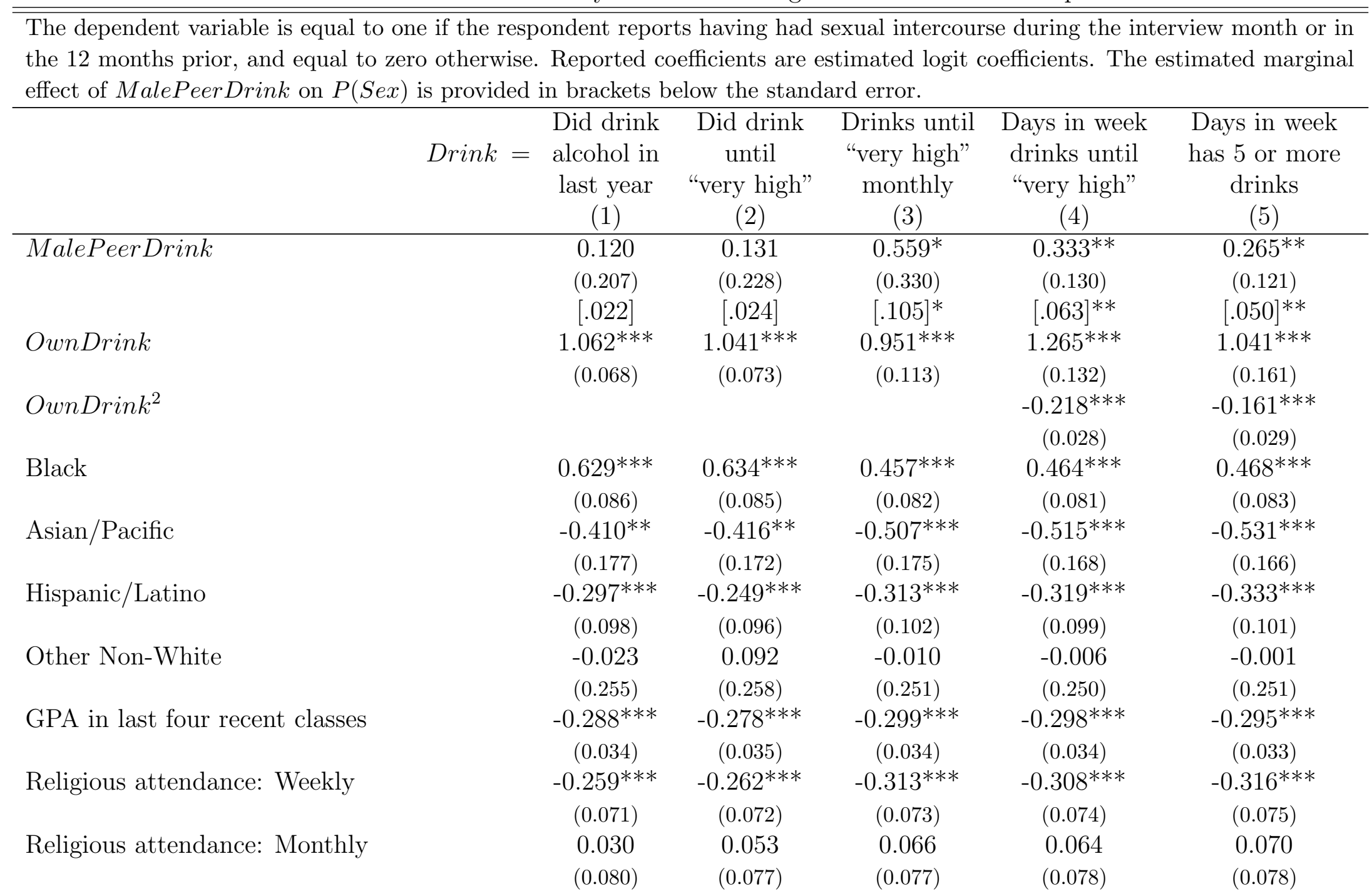


Table 5: Continued...

\begin{tabular}{|c|c|c|c|c|c|c|}
\hline & Drink $=$ & $\begin{array}{l}\text { Did drink } \\
\text { alcohol in } \\
\text { last year } \\
(1)\end{array}$ & $\begin{array}{l}\text { Did drink } \\
\text { until } \\
\text { "very high" } \\
(2)\end{array}$ & $\begin{array}{l}\text { Drinks until } \\
\text { "very high" } \\
\text { monthly } \\
(3)\end{array}$ & $\begin{array}{l}\text { Days in week } \\
\text { drinks until } \\
\text { "very high" } \\
(4)\end{array}$ & $\begin{array}{c}\text { Days in week } \\
\text { has } 5 \text { or more } \\
\text { drinks } \\
(5)\end{array}$ \\
\hline Religious attendance: Some & & -0.075 & -0.053 & -0.036 & -0.034 & -0.041 \\
\hline & & $(0.074)$ & $(0.076)$ & $(0.075)$ & $(0.074)$ & $(0.074)$ \\
\hline Sex included in ideal relationship & & $\begin{array}{c}1.618^{* * *} \\
(0.060)\end{array}$ & $\begin{array}{c}1.599^{* * *} \\
(0.062)\end{array}$ & $\begin{array}{c}1.697^{* * *} \\
(0.067)\end{array}$ & $\begin{array}{c}1.687^{* * *} \\
(0.067)\end{array}$ & $\begin{array}{c}1.694^{* * *} \\
(0.067)\end{array}$ \\
\hline Constant & & $\begin{array}{c}-4.333^{* * *} \\
(0.503)\end{array}$ & $\begin{array}{c}-4.140^{* * *} \\
(0.517)\end{array}$ & $\begin{array}{c}-3.846^{* * *} \\
(0.510)\end{array}$ & $\begin{array}{c}-3.893^{* * *} \\
(0.509)\end{array}$ & $\begin{array}{c}-3.903^{* * *} \\
(0.511)\end{array}$ \\
\hline Observations & & 9482 & 9482 & 9482 & 9482 & 9482 \\
\hline
\end{tabular}

Standard errors in parentheses, corrected for clustering at the school level; ${ }^{* *} \mathrm{p}<0.01,{ }^{* *} \mathrm{p}<0.05,{ }^{*} \mathrm{p}<0.1$. All specifications include grade and age fixed effects, controls for parent education (i.e., indicator variables for high school, some college, bachelor, graduate/professional), and county-level measures of the proportion urban, proportion rural, and unemployment rate. 
Table 6: Within-school variation in male sexual activity and female-peer drinking

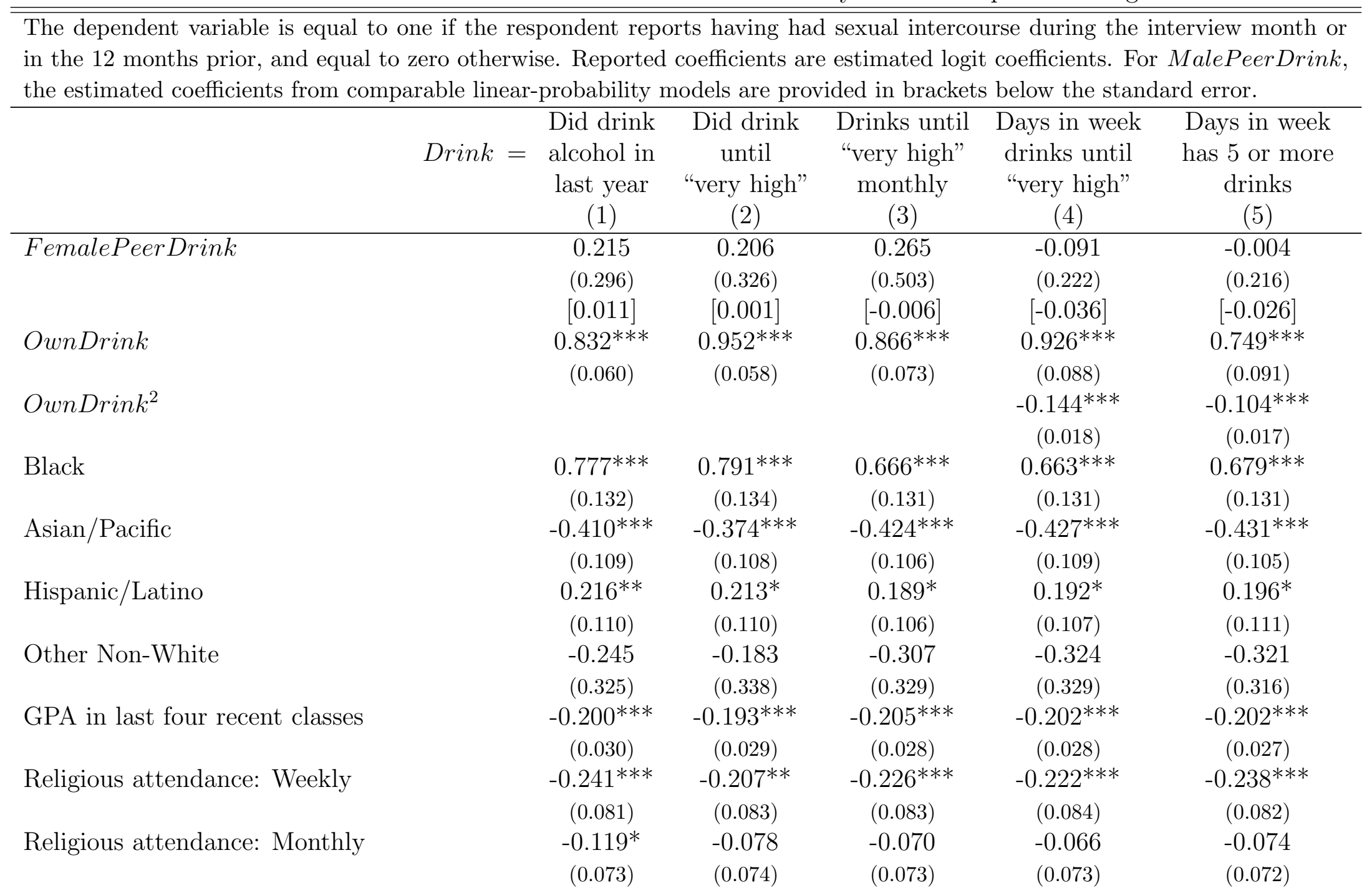


Table 6: Continued...

\begin{tabular}{|c|c|c|c|c|c|}
\hline & $\begin{array}{c}\text { Did drink } \\
\text { alcohol in } \\
\text { last year } \\
(1)\end{array}$ & $\begin{array}{l}\text { Did drink } \\
\text { until } \\
\text { "very high" } \\
(2)\end{array}$ & $\begin{array}{l}\text { Drinks until } \\
\text { "very high" } \\
\text { monthly } \\
(3)\end{array}$ & $\begin{array}{l}\text { Days in week } \\
\text { drinks until } \\
\text { "very high" } \\
(4)\end{array}$ & $\begin{array}{c}\text { Days in week } \\
\text { has } 5 \text { or more } \\
\text { drinks } \\
(5)\end{array}$ \\
\hline \multirow[t]{2}{*}{ Religious attendance: Some } & -0.050 & -0.045 & 0.014 & 0.019 & -0.006 \\
\hline & $(0.077)$ & $(0.079)$ & $(0.075)$ & $(0.076)$ & $(0.077)$ \\
\hline \multirow[t]{2}{*}{ Sex included in ideal relationship } & $1.621^{* * *}$ & $1.580^{* * *}$ & $1.675^{* * *}$ & $1.673^{* * *}$ & $1.671^{* * *}$ \\
\hline & $(0.052)$ & $(0.052)$ & $(0.054)$ & $(0.053)$ & $(0.053)$ \\
\hline Observations & 8890 & 8890 & 8890 & 8890 & 8890 \\
\hline
\end{tabular}


Table 7: Within-school variation in female sexual activity and male-peer drinking

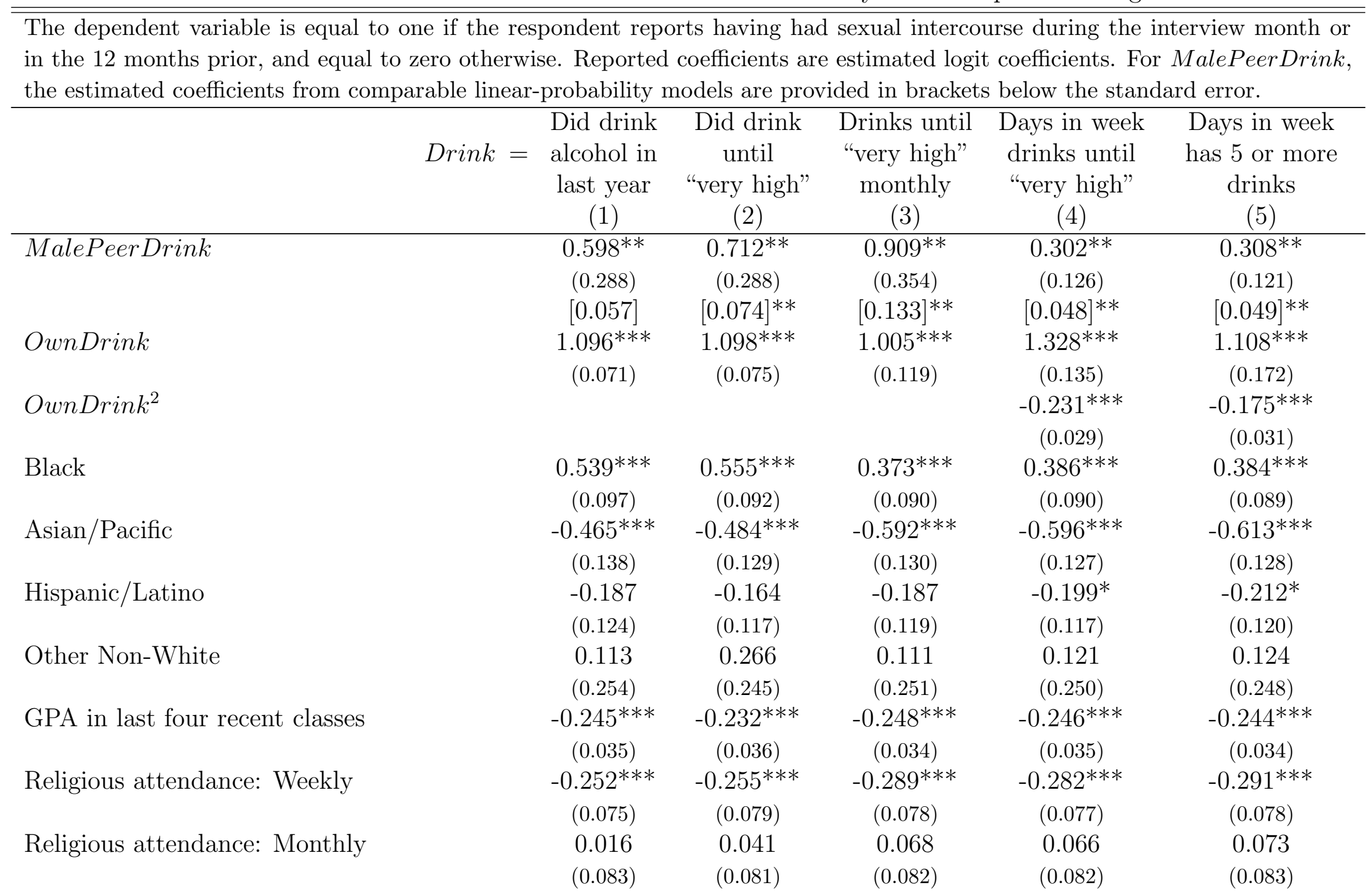


Table 7: Continued...

\begin{tabular}{|c|c|c|c|c|c|}
\hline & $\begin{array}{c}\text { Did drink } \\
\text { alcohol in } \\
\text { last year } \\
(1)\end{array}$ & $\begin{array}{l}\text { Did drink } \\
\text { until } \\
\text { "very high" } \\
(2)\end{array}$ & $\begin{array}{l}\text { Drinks until } \\
\text { "very high" } \\
\text { monthly } \\
(3)\end{array}$ & $\begin{array}{l}\text { Days in week } \\
\text { drinks until } \\
\text { "very high" } \\
(4)\end{array}$ & $\begin{array}{c}\text { Days in week } \\
\text { has } 5 \text { or more } \\
\text { drinks } \\
(5)\end{array}$ \\
\hline \multirow[t]{2}{*}{ Religious attendance: Some } & -0.053 & -0.027 & -0.003 & 0.001 & -0.011 \\
\hline & $(0.076)$ & $(0.079)$ & $(0.076)$ & $(0.075)$ & $(0.076)$ \\
\hline \multirow[t]{2}{*}{ Sex included in ideal relationship } & $1.665^{* * *}$ & $1.649^{* * *}$ & $1.756^{* * *}$ & $1.748^{* * *}$ & $1.752^{* * *}$ \\
\hline & $(0.061)$ & $(0.062)$ & $(0.066)$ & $(0.067)$ & $(0.067)$ \\
\hline Observations & 9384 & 9384 & 9384 & 9384 & 9384 \\
\hline
\end{tabular}


Table 8: Does female-peer drinking have similar effect?

The dependent variable is equal to one if the respondent reports having had sexual intercourse during the interview month or in the 12 months prior, and equal to zero otherwise. Reported coefficients are estimated logit coefficients.

\begin{tabular}{|c|c|c|c|c|c|c|}
\hline & Drink $=$ & $\begin{array}{l}\text { Did drink } \\
\text { alcohol in } \\
\text { last year } \\
(1)\end{array}$ & $\begin{array}{l}\text { Did drink } \\
\text { until } \\
\text { "very high" } \\
(2)\end{array}$ & $\begin{array}{l}\text { Drinks until } \\
\text { "very high" } \\
\text { monthly } \\
(3)\end{array}$ & $\begin{array}{l}\text { Days in week } \\
\text { drinks until } \\
\text { "very high" } \\
(4)\end{array}$ & $\begin{array}{c}\text { Days in week } \\
\text { has } 5 \text { or more } \\
\text { drinks } \\
(5)\end{array}$ \\
\hline \multicolumn{7}{|l|}{ A: Pooled } \\
\hline \multirow[t]{2}{*}{ MalePeerDrink } & & 0.152 & 0.295 & 0.527 & $0.333^{* *}$ & $0.261^{* *}$ \\
\hline & & $(0.219)$ & $(0.250)$ & $(0.327)$ & $(0.130)$ & $(0.119)$ \\
\hline \multirow[t]{2}{*}{ FemalePeerDrink } & & -0.100 & -0.421 & 0.213 & 0.071 & 0.067 \\
\hline & & $(0.258)$ & $(0.285)$ & $(0.495)$ & $(0.215)$ & $(0.170)$ \\
\hline Observations & & 9482 & 9482 & 9482 & 9482 & 9482 \\
\hline \multicolumn{7}{|c|}{ B: School fixed effects } \\
\hline \multirow[t]{2}{*}{ MalePeerDrink } & & $0.551^{*}$ & $0.723^{* *}$ & $0.853^{* *}$ & $0.305^{* *}$ & $0.308^{* *}$ \\
\hline & & $(0.303)$ & $(0.291)$ & $(0.354)$ & $(0.125)$ & $(0.121)$ \\
\hline \multirow[t]{2}{*}{ FemalePeerDrink } & & 0.227 & -0.054 & $0.900^{*}$ & 0.105 & 0.042 \\
\hline & & $(0.294)$ & $(0.306)$ & $(0.512)$ & $(0.245)$ & $(0.178)$ \\
\hline Observations & & 9384 & 9384 & 9384 & 9384 & 9384 \\
\hline
\end{tabular}


Table 9: Does the influence of male peers on females attenuate for those with homosexual preference?

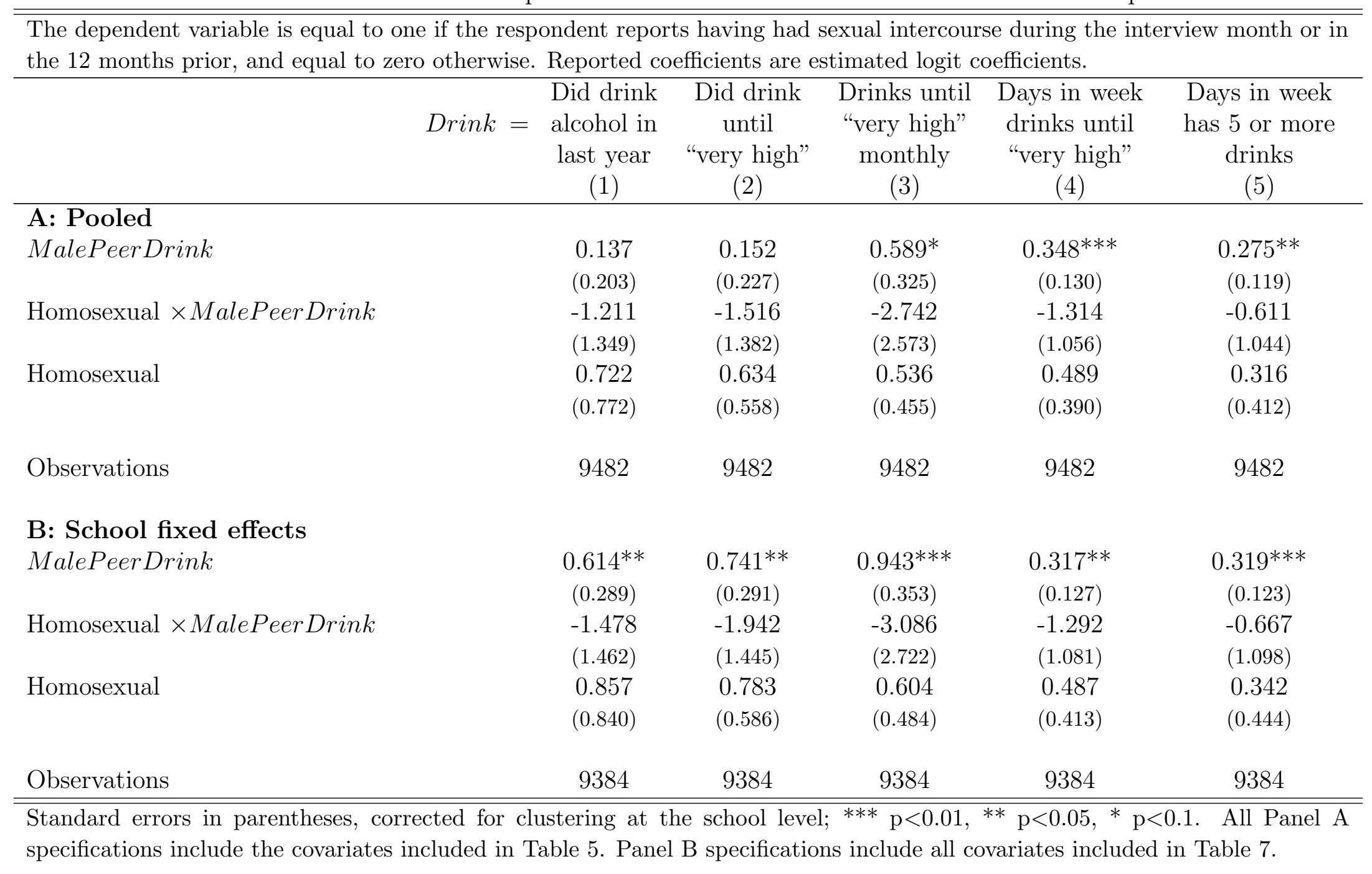


Table 10: Is female sexual activity responsive to other anti-social behaviors exhibited by male peers?

The dependent variable is equal to one if the respondent reports having had sexual intercourse during the interview month or in the 12 months prior, and equal to zero otherwise. Reported coefficients are estimated logit coefficients.

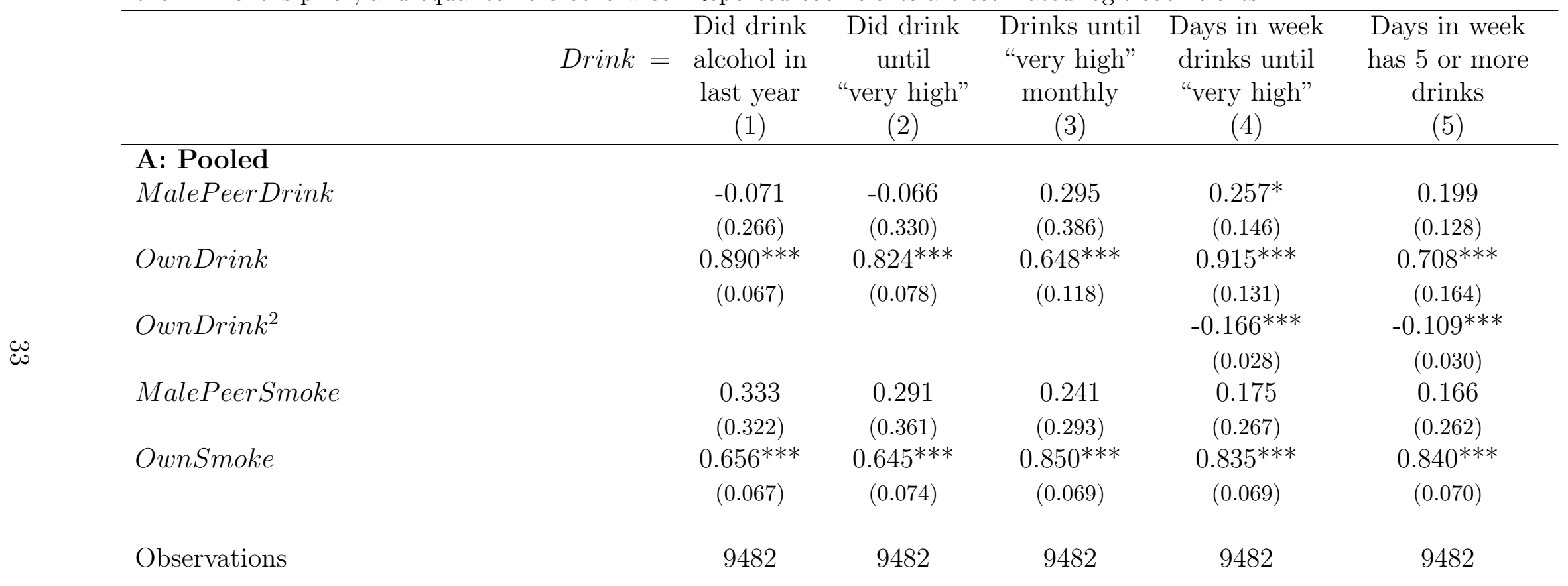


Table 10: Continued...

(1)

$(3)$

(4)

(5)

\section{B: School fixed effects}

MalePeerDrink

$\begin{array}{ccccc}0.604^{* *} & 0.801^{* * *} & 0.882^{* *} & 0.252^{*} & 0.255^{* *} \\ (0.299) & (0.298) & (0.390) & (0.138) & (0.129) \\ 0.928^{* * *} & 0.887^{* * *} & 0.712^{* * *} & 0.990^{* * *} & 0.789^{* * *} \\ (0.070) & (0.080) & (0.126) & (0.134) & (0.174) \\ & & & -0.180^{* * *} & -0.126 * * * \\ -0.012 & -0.145 & 0.076 & (0.029) & (0.031) \\ (0.335) & (0.341) & (0.352) & 0.227 & 0.177 \\ 0.647^{* * *} & 0.633^{* * *} & 0.849 * * * & 0.835 * * * & (0.345) \\ (0.069) & (0.076) & (0.071) & (0.072) & 0.836^{* * *} \\ & & & & (0.071)\end{array}$

\section{OwnDrink}

OwnDrink ${ }^{2}$

MalePeerSmoke

OwnSmoke

$(0.069)$

(0.076)

$(0.071)$

$(0.072)$

9384

Standard errors in parentheses, corrected for clustering at the school level; ${ }^{* * *} \mathrm{p}<0.01,{ }^{* *} \mathrm{p}<0.05,{ }^{*} \mathrm{p}<0.1$. All Panel A specifications include the covariates included in Table 5. Panel B specifications include all covariates included in Table 7. 